Revista Ciências Exatas e Naturais, Vol.20, nº.1, Jan/Jun, 2018

\title{
Oficinas de Probabilidade e Estatística: Uma proposta de intervenção no ensino e aprendizagem de Matemática
}

\section{Workshops of probability and statistics: a proposal for intervention in the teaching and learning of mathematics}

\author{
Mailson Matos Pereira \\ Universidade Universidade Estadual da Paraíba - UEPB, Campina Grande, PB \\ mailsonpb@hotmail.com \\ Divanilda Maia Esteves \\ Universidade Universidade Estadual da Paraíba - UEPB, Campina Grande, PB \\ diana.maia@gmail.com
}

Resumo: Este trabalho tem como principal objetivo apresentar os resultados de uma abordagem diferenciada dos conteúdos de Probabilidade e Estatística no ensino médio. Para atingir o objetivo foram aplicadas cinco oficinas de Matemática com os alunos do $3^{\circ}$ ano da Escola Estadual de Ensino Fundamental e Médio Arruda Câmara localizada na cidade de Pombal-PB. A aplicação das oficinas tinha como finalidade desenvolver nos educandos um novo olhar sobre a matemática, fazer com que os mesmos fossem capazes de compreender conceitos probabilísticos e estatísticos, construir e fazer leitura de gráficos e tabelas, bem como associar e utilizar a Estatística e a Probabilidade a situações cotidianas. No decorrer do trabalho, serão apresentados: a descrição das oficinas, sua aplicação e os resultados obtidos. Por fim, serão feitas algumas considerações sobre os resultados observados.

Palavras-chave: Oficinas; Estatística; Probabilidade; Ensino e Aprendizagem.

\begin{abstract}
The main objective of this work is to present the results of a differentiated approach to probability and statistics in secondary education. In order to reach the objective, five activities were applied with the students of the $3^{\circ}$ year of the State School of Elementary and Middle Arruda Câmara located at the city of Pombal-PB. The purpose of the activities was to develop a new look at mathematics, to enable them to better understand probabilistic and statistical concepts, to construct and read graphs and tables, and to associate and use statistics and Probability in their lifes. In this work, the following will be presented: a description of the workshops, their application and the results obtained. We will present the class profile and the impressions of the students about the impact of the work on their learning.
\end{abstract}

Key words: Workshops; Probability; Statistics; Education and Learning.

\section{Introdução}

Diariamente ouvimos falar, pelos veículos de comunicação em bolsa de valores, crescimento populacional, taxa de natalidade, loterias esportivas e numéricas, pesquisas de opinião pública, entre outros. Tudo isso está diretamente ligado a um campo da Matemática que 
trabalha com o tratamento de informações conhecido como Estatística. A estatística é a parte da Matemática em que se investigam processos de obtenção, organização e análise de dados sobre um Universo populacional - (coleção de seres quaisquer), e métodos de tirar conclusões e tomar decisões com base nestes dados, ou ainda um conjunto de elementos numéricos relativos a um fator Social [8].

De acordo com as Leis Diretrizes e Base da Educação (LDB), a Educação Básica tem por principal objetivo promover uma formação comum indispensável para o exercício da cidadania [2]. Assim, fica claro que o estudo da Estatística é de fundamental importância para a formação inicial, visto que, de acordo com os Parâmetros Curriculares Nacionais (PCN) estudar Estatística e Probabilidade favorece o desenvolvimento de certas atitudes, como posicionar-se criticamente, fazer previsões e tomar decisões ante as informações vinculadas pela mídia, livros, jornais e outras fontes.

Os PCN estabelecem que o aluno deve ser capaz de compreender acontecimentos do cotidiano que são de natureza aleatória, construir conceitos, ler e interpretar dados de gráficos e tabelas entre outros; sendo sempre capaz de observar aspectos que permitam confiar ou não nos resultados observados [3].

Neste sentido, este trabalho tem o propósito de trazer uma proposta de intervenção para o ensino e aprendizagem de Estatística e Probabilidade utilizando-se de práticas interdisciplinares com auxílio lúdico e tecnológico em alguns momentos. Estas aulas devem ser ministradas através de Oficinas Matemáticas que façam com que os alunos compreendam de forma mais efetiva conceitos, tais como: espaço amostral, probabilidade, inferência, média, moda, mediana, variância, desvio-padrão, entre outros. Na maioria das vezes, a forma como o conteúdo de Probabilidade e Estatística é ministrado faz com que os alunos decorem fórmulas e procedimentos algébricos destes conteúdos, deixando de lado o essencial, que são seu significado e suas aplicações cotidianas.

A abordagem é destinada a professores que ministram aulas de Matemática para turmas de Ensino Fundamental II e Médio. A mesma procura estabelecer a importância do ensino e aprendizagem de Estatística e Probabilidade e da utilização de práticas inovadoras, objetivando promover uma melhor aprendizagem e interação entre professor e aluno. Esse tipo de atividade tem sido utilizado com sucesso em diversas áreas, pois dinamiza as aulas e atrai a atenção do aluno. Por exemplo, em [1] trabalhou-se os conceitos de estatística através da construção de questionários. Os alunos traçaram o perfil dos alunos da escola onde estudavam e apresentaram os resultados usando estatística descritiva. $\mathrm{O}$ autor relata o envolvimento e a motivação da sala ao realizar a tarefa e a forma como assimilaram mais facilmente o conteúdo. Outra experiência, relatada por [5], faz o uso de um jogo com questões de probabilidade em diferentes níveis onde os alunos podiam testar o que aprenderam nas aulas de probabilidade. Vale ressaltar, que essas atividades devem ser usadas conjuntamente com as aulas teóricas. Seu objetivo é auxiliar na aprendizagem, pois uma vez que o aluno aplica o conteúdo ministrado, ele solidifica esse conhecimento adquirido.

O projeto foi testado na Escola Estadual de Ensino Fundamental e Médio Arruda Câmara localizada na cidade de Pombal-PB, no Sertão Paraibano. Foram aplicadas Oficinas Matemáticas de Estatística e Probabilidade com alunos do $3^{\circ}$ ano do Ensino Médio da referida escola, cuja forma de aplicação e os resultados serão apresentados neste artigo. 
Revista Ciências Exatas e Naturais, Vol.20, nº.1, Jan/Jun, 2018

\section{As Oficinas}

Não há dúvidas de que a matemática faz parte do dia a dia de todos, no entanto a forma como muitas vezes é abordada nas escolas, faz com que muita gente acredite que este é um conteúdo abstrato, inacessível e quase incompreensível. No entanto, sabe-se que o uso de material concreto no ensino de matemática tem mudado um pouco esta visão. No que se refere ao ensino de Estatística e Probabilidade, a Associação Brasileira de Estatística (ABE) e o Instituto Brasileiro de Geografia e Estatística (IBGE) tem promovido ações no sentido de divulgar (a Estatística) e buscar alternativas para dinamizar o ensino. A ABE criou o "Projeto Bussab de Divulgação e Educação Estatística" e tem discutido com seus membros a respeito de propostas que possam tornar mais atrativos os conteúdos relacionados a essa área específica. Mais informações podem ser obtidas no site da associação (http://www.redeabe.org.br/site/). O IBGE tem o projeto Portas Abertas para a Escola, que é um evento online com palestras de pesquisadores e professores, falando sobre experiências do ensino de estatística na educação básica e apresentando propostas de atividades (https://eventos.ibge.gov.br/escolas-online). Além dessas iniciativas, pode-se citar o portal Ativestat (https://www.ime.usp.br/ativestat) que é um projeto do professor Marcos N. Magalhães do Instituto de Matemática e Estatística da Universidade de São Paulo. No site, o professor, que é pesquisador da área de Educação Estatística, sugere algumas oficinas que podem ser realizadas em sala de aula para dinamizar o ensino na área.

A Estatística pode ser dividida em duas partes: a Estatística Descritiva, que trabalha com a descrição e organização dos dados e a Estatística Indutiva ou Inferencial, que faz a análise e interpretação desses dados e tenta tirar conclusões sobre populações, a partir de resultados obtidos com testes estatísticos feitos em amostras retiradas dessa população. A base do conhecimento estatístico é a probabilidade. Na educação básica, o enfoque maior é dado aos conceitos de estatística descritiva (tabelas, gráficos e medidas resumo) e probabilidade para espaços amostrais finitos.

No ensino médio de escolas públicas os alunos acabam enfrentando dificuldades no ensino e aprendizagem de Estatística; muitas vezes por falta de base que deveria ser adquirida no ensino fundamental ou mesmo porque os professores preferem não ministrar este conteúdo. Isso tudo faz com que os estudantes tenham dificuldade em interpretar gráficos e tabelas que aparecem com grande frequência no Exame Nacional do Ensino Médio (ENEM), em provas de concursos públicos, seleções de cursos técnicos, entre outros. Este é um dos pontos importantes do estudo de Estatística e Probabilidade na educação básica [1]. Além disso, claramente, conhecer os conceitos de probabilidade e estatística influencia na formação do cidadão, pois contribui para uma melhor leitura de informações recebidas através de gráficos, tabelas e medidas como médias e porcentagens. Tal apresentação de dados tem sido amplamente usadas por meios de comunicação, propagandas governamentais, pesquisadores, por exemplo.

As oficinas aqui apresentadas buscam unir o aspecto multidisciplinar inerente à estatística/probabilidade e a motivação presente nos processos de aprendizagem que fogem

das aulas teóricas. É necessário esclarecer que as aulas teóricas são importantes e que elas aconteceram antes da aplicação das atividades. A atividade proposta reforça os conceitos através de sua aplicação em situações práticas.

Os conceitos abordados nas oficinas podem ser encontrados em diversos livros tanto em nível de educação básica, quanto superior. Eles foram apresentados com detalhes no trabalho que originou este artigo [8], bem como em livros como [4, 6, 7, 9, 10].

A seguir serão apresentadas as oficinas e alguns comentários adicionais sobre sua aplicação. 


\subsection{Oficina 1 - Horas dormidas}

Inicialmente houve um debate entre o professor e os estudantes sobre o que pode interferir na quantidade de horas dormidas, no qual algumas questões sobre o tema foram levantadas, como por exemplo:

- Será que meninos dormem mais do que meninas?

- Quem pratica esporte dorme mais?

- Quem passa muito tempo na internet dorme menos?

Depois da discussão, decidiu-se quais variáveis seriam consideradas. Para evitar complicações na análise, decidiu-se que a variável horas dormidas deveria ser anotada em valores inteiros (aproximados) de horas. O próximo passo foi coletar dados. A seguir, em sala de aula o professor junto com os estudantes, construíram tabelas e gráficos (de setores, de barras, de segmentos entre outros) com as frequências de cada variável coletada utilizando computadores ou papel e lápis. Para finalizar, os alunos observaram e comentaram em grupos o comportamento das variáveis, com base nas tabelas e gráficos.

Pode-se ainda estudar o efeito das outras variáveis sobre as horas dormidas. Por exemplo, faça um gráfico separado para cada resposta sobre prática de esportes; isto é, compare as horas de sono dos que praticam com os que não praticam esportes e verifique se aparecem diferenças. Peça que os estudantes comentem. De modo similar, estude a influência das outras variáveis que tiverem sido coletadas. A aula pode culminar com uma reflexão sobre os resultados e as dificuldades encontradas. Pode-se questionar por exemplo:

- Qual a conclusão da influência de cada variável estudada?

- Encontraram alguma coisa que tende a atrapalhar a quantidade de horas dormidas?

- Algum fator existente aumenta essas horas?

Esta oficina é uma versão adaptada de uma atividade proposta no Ativestat - Instituto de Matemática e Estatística da Universidade de São Paulo, disponível no site https: //www.ime.usp.br/ativestat. A mesma foi realizada em 4 horas/aula e foi dividida em duas etapas, onde na primeira foi feito o levantamento dos dados e na segunda foi feita a discussão dos resultados.

\subsection{Oficina 2 - Argumentação com números}

O objetivo desta atividade é explorar a coleta de informações pelos estudantes para dar suporte às suas opiniões. Esta atividade não visa apenas reproduzir argumentos encontrados em algumas fontes pesquisadas, mas sim, reforçar as suas opiniões sobre determinados temas utilizando-se de dados estatísticos para fortalecer a sua tese.

Esta pode ser considerada uma das melhores formas de um estudante entender a importância da estatística em seu cotidiano e o quanto a mesma está presente na sociedade. Esta oficina consiste em fazer com que os alunos busquem defender pontos de vistas fundamentando-se em dados estatísticos e deve ser aplicada em duas aulas.

Na primeira aula o professor propôs alguns conteúdos atuais e polêmicos, de preferência que deixem os estudantes com opiniões divididas, tais como:

- Permissão para dirigir aos 16 anos; 
Revista Ciências Exatas e Naturais, Vol.20, nº.1, Jan/Jun, 2018

- Uso de celular em sala de aula;

- Legalização do aborto;

- Escolas em tempo integral;

- Maioridade penal aos 16 anos;

entre outros temas, que podem ser sugeridos pelos próprios educandos.

Em seguida, os alunos escolhem um ou dois temas, dependendo da quantidade de alunos da classe. Escolhidos o(s) tema(s), divide-se a sala em grupos, sendo que um dos grupos deve apresentar argumentos a favor do tema e o outro contra. Ainda nessa aula são discutidos os meios(fontes) que cada grupo vai se utilizar para embasar suas argumentações. O professor, deve dar o prazo de uma semana para que os alunos possam pesquisar, ou até mesmo fazer pesquisas de opinião, sobre os posicionamentos que pretendem defender.

$\mathrm{Na}$ segunda aula, que deve ocorrer uma semana depois, o professor, deve conduzir um debate entre os grupos, onde cada um deve expor os argumentos pesquisados. Eles devem usar gráficos, tabelas e outros meios estatísticos para enriquecer a apresentação. Depois de cada grupo defender seu ponto de vista, o professor deve dar um tempo para que o restante da turma possa se posicionar a respeito do tema levando em consideração os argumentos apresentados.

Esta atividade também é adaptada de Ativestat - Instituto de Matemática e Estatística da Universidade de São Paulo e está disponível no site https://www.ime.usp.br/ativestat. A mesma reflete o quanto a matemática está presente em nossas vidas e também é uma excelente forma de se trabalhar a interdisciplinaridade em sala de aula.

\subsection{Oficina 3 - Quem tem melhor noção de medida?}

Esta atividade tem como objetivo reforçar a compreensão de conceitos como média, moda, mediana, variância, amplitude e desvio padrão. Isto é importante porque muitos alunos aprendem a calcular estas medidas de forma mecânica, através de procedimentos algébricos, mas não compreendem suas definições e significados.

Nesta oficina os alunos foram divididos em dois grupos meninos e meninas, em que cada participante de cada um dos dois grupos deve retirar de uma fita um tamanho pré determinado, sem o auxílio de qualquer instrumento de medida, ou seja, apenas pela ideia que o mesmo tenha do tamanho fixado.

Depois que todos os alunos tiverem retirado seus pedaços de fita, com o auxílio de uma fita métrica, deve-se observar e anotar todos os valores, separando entre medidas obtidas pelo grupo 1 e grupo 2. Em seguida, observamos qual grupo chegou mais perto da medida desejada.

Para isto, o professor deve pedir que os alunos de um grupo calculem medidas de tendência central - (média, moda e mediana) e medidas de dispersão - (amplitude, variância e desvio padrão) dos valores do outro grupo.

Feito os cálculos, o professor deve anotar os valores obtidos no quadro, relembrar com os alunos os conceitos dos valores que foram calculados e definir qual grupo teve mais regularidade na procura pelo determinado valor.

Esta oficina foi uma ideia dos autores. 


\subsection{Oficina 4 - Seu dado é honesto?}

Inicialmente os alunos formaram duplas e a cada dupla foi entregue um dado (podendo ser honesto ou não) cuja probabilidade de ocorrência de cada face é desconhecida. Os estudantes deviam lançar esse dado seis vezes e, com base nos resultados obtidos dizer se eles achavam que o dado era honesto ou não. Cada dupla de estudantes deve construir uma tabela anotando todos os seis resultados antes de responder o questionamento:(Seu dado é honesto?). Por fim, o professor constrói uma tabela no quadro onde anota os resultado e as conclusões de cada dupla, nos moldes da Tabela 1.

Tabela 1. Tabela de frequências construída com dados hipotéticos sobre lançamentos de dados.

\begin{tabular}{c|c|c|c|c|c|c|c}
\hline Face & 1 & 2 & 3 & 4 & 5 & 6 & Honesto \\
\hline Resultado da dupla 1 & 2 & 1 & 0 & 1 & 0 & 2 & Sim \\
Resultado da dupla 2 & 3 & 1 & 0 & 1 & 1 & 0 & Não \\
$\vdots$ & $\vdots$ & $\vdots$ & $\vdots$ & $\vdots$ & $\vdots$ & $\vdots$ & $\vdots$ \\
\hline & Fonte:[8].
\end{tabular}

Terminada a construção, o professor promove uma discussão geral que apresenta os conceitos de inferência e aleatoriedade, mencionando que seis lançamentos é uma quantidade insuficiente para concluir sobre a honestidade de um dado, pois o erro envolvido na estimação é muito grande.

Como não é possível fazer infinitos lançamentos para chegar a uma conclusão, a inferência estatística pode estabelecer tamanhos de amostras para chegarmos a uma proximidade do que queremos, ou seja, quanto maior o espaço amostral em uma pesquisa ou experimento, mais próximo chegamos do resultado real.

Esta atividade foi retirada de Ativestat e está disponível no site https://www.ime.usp. br/ativestat. A mesma explora intuitivamente ideias de aleatoriedade e inferência sem entrar em detalhes técnicos, que são apresentados no nível superior.

\subsection{Oficina 5 - Jogo da mini trilha}

A oficina trabalhou conceitos de probabilidade e o uso de inferência informal. A mesma é inspirada no Jogo de Trilha. Nesta oficina o professor divide a turma em duplas e pede que cada dupla jogue 10 partidas de um jogo de trilha com 4 casas. Cada partida consiste em mover um peão (grão de milho ou feijão) pela trilha toda, desde a casa "início" até chegar ou ultrapassar a casa "4". Cada estudante da dupla escolhe a sua face de uma moeda (cara ou coroa). A dupla de estudantes lança a moeda e move o peão na trilha de acordo com o resultado do lançamento. Se o resultado for cara, o peão anda 1 casa; se for coroa, anda 2 casas. Este procedimento é repetido até que o peão alcance ou ultrapasse a $4^{\mathrm{a}}$ casa (terminando a rodada). Marca um ponto o estudante que tiver escolhido a face obtida no último lance da rodada, isto é, a face resultante no lance que fez o peão atingir ou ultrapassar a casa " 4 ". As rodadas são repetidas 10 vezes e a dupla deve anotar a face vencedora.

Após as 10 rodadas, a dupla calcula a frequência relativa das ocorrências das faces vencedoras. Em seguida, o professor pede aos alunos um palpite sobre qual seria a probabilidade de vitória de cada face num próximo jogo. Nesse caso, os estudantes estão fazendo uma 
Revista Ciências Exatas e Naturais, Vol.20 , nº.1, Jan/Jun, 2018

inferência informal sobre a probabilidade de ganhar com a moeda utilizada pela dupla. Peça que reflitam sobre a confiança nesse palpite: quanto maior o número de lançamentos maior a confiança?

Na sequência, pergunta-se: qual é o valor da probabilidade de vencer usando uma moeda honesta (equilibrada)? O professor aguarda os estudantes trabalharem e pode fazer o cálculo na lousa utilizando probabilidade condicional ou a árvore das possibilidades.

Calculando-se as probabilidades de vitória de cada face, obtém-se:

$$
\begin{gathered}
P(\text { vitória de cara })=\frac{5}{16} \approx 0,3125, \\
P(\text { vitória de coroa })=\frac{11}{16} \approx 0,6875 .
\end{gathered}
$$

O professor discute com os estudantes sobre a relação entre a frequência relativa obtida com a moeda lançada e o cálculo acima. A discussão aqui envolve refletir sobre a honestidade das moedas que foram lançadas e observar que quanto maior for o número de lançamentos de uma moeda honesta, maior será a proximidade da probabilidade desejada. Esta atividade foi proposta pelo projeto Ativestat e está disponível no site https://www.ime.usp.br/ativestat.

\section{Resultados e discussão}

A oficinas foram aplicadas em uma turma de $3^{\circ}$ ano do ensino médio da Escola Estadual de Ensino Fundamental e Médio Arruda Câmara. Essa escola localiza-se no município de Pombal, no Sertão da Paraíba, às margens da BR-230. Sua infraestrutura é boa, pois a mesma acaba de passar por uma reforma e recentemente foi climatizada. A turma tem 22 alunos com idades entre 15 e 18 anos. Nem todos os alunos da turma gostam de matemática e, na maioria das vezes, isso se dá por falta de motivação ou deficiência na aprendizagem.

\subsection{Aplicação da Oficina 1}

Inicialmente, foi ministrada uma aula sobre tabelas e gráficos. Em seguida, o professor iniciou uma discussão sobre o número de horas dormidas e sua influência em outras atividades, se utilizando das indagações propostas na descrição da oficina. Em meio à discussão foi decidido que cada aluno responderia as seguintes perguntas:

- Quantas horas você dorme por dia?

- Você fica na Internet até tarde da noite?

- Você pratica esporte ou algum outro tipo de atividade física?

Após todos os alunos responderem os questionamentos, o professor construiu no quadro uma tabela anotando os resultados de cada educando obtendo como resultado os dados da Tabela 2. Nesta tabela, o gênero representado por feminino - $(\mathbf{F})$ ou masculino - (M), e em prática de atividade física (coluna 4), e tempo na internet (coluna 5), representa-se sim e não, respectivamente por $(\mathbf{S})$ e $(\mathbf{N})$.

Dando continuidade, os alunos foram convidados a construir gráficos de setores e barras utilizando os dados da tabela. Os mesmos optaram por fazer esta atividade usando computador. Um desses gráficos pode ser visto na Figura 1. 
Tabela 2. Tabela de frequências construída com dados sobre os alunos do $3^{\circ} B$.

\begin{tabular}{l|c|c|c|c}
\hline Aluno & Gênero & $\begin{array}{c}\text { Quantidade de } \\
\text { horas dormidas }\end{array}$ & $\begin{array}{c}\text { Pratica Atividade } \\
\text { física }\end{array}$ & $\begin{array}{c}\text { Fica até tarde } \\
\text { na Internet }\end{array}$ \\
\hline Aluno 1 & $\mathrm{F}$ & 7 & $\mathrm{~N}$ & $\mathrm{~S}$ \\
Aluno 2 & $\mathrm{F}$ & 6 & $\mathrm{~N}$ & $\mathrm{~S}$ \\
Aluno 3 & $\mathrm{M}$ & 8 & $\mathrm{~N}$ & $\mathrm{~S}$ \\
Aluno 4 & $\mathrm{F}$ & 6 & $\mathrm{~N}$ & $\mathrm{~S}$ \\
Aluno 5 & $\mathrm{F}$ & 10 & $\mathrm{~N}$ & $\mathrm{~S}$ \\
Aluno 6 & $\mathrm{M}$ & 8 & $\mathrm{~N}$ & $\mathrm{~S}$ \\
Aluno 7 & $\mathrm{M}$ & 5 & $\mathrm{~S}$ & $\mathrm{~S}$ \\
Aluno 8 & $\mathrm{M}$ & 8 & $\mathrm{~N}$ & $\mathrm{~S}$ \\
Aluno 9 & $\mathrm{M}$ & 8 & $\mathrm{~N}$ & $\mathrm{~S}$ \\
Aluno 10 & $\mathrm{M}$ & 2 & $\mathrm{~N}$ & $\mathrm{~S}$ \\
Aluno 11 & $\mathrm{M}$ & 5 & $\mathrm{~S}$ & $\mathrm{~S}$ \\
Aluno 12 & $\mathrm{M}$ & 7 & $\mathrm{~N}$ & $\mathrm{~N}$ \\
Aluno 13 & $\mathrm{F}$ & 5 & $\mathrm{~S}$ & $\mathrm{~S}$ \\
Aluno 14 & $\mathrm{M}$ & 6 & $\mathrm{~S}$ & $\mathrm{~S}$ \\
Aluno 15 & $\mathrm{M}$ & 7 & $\mathrm{~S}$ & $\mathrm{~N}$ \\
Aluno 16 & $\mathrm{M}$ & 7 & $\mathrm{~N}$ & $\mathrm{~S}$ \\
Aluno 17 & $\mathrm{F}$ & 9 & $\mathrm{~S}$ & $\mathrm{~N}$ \\
Aluno 18 & $\mathrm{M}$ & $\mathrm{N}$ & $\mathrm{N}$ & $\mathrm{N}$ \\
Aluno 19 & $\mathrm{F}$ & 5 & $\mathrm{~S}$ \\
\hline \multicolumn{2}{l}{ Fonte:[8]. }
\end{tabular}

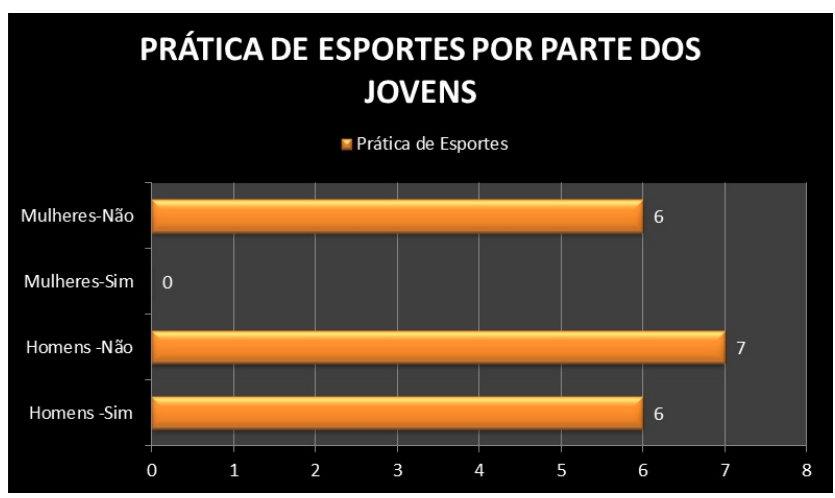

Figura 1. Gráfico de barras construído na oficina 1 com dados da Tabela 2.

Em seguida, os educandos discutiram os resultados da pesquisa analisando se a prática de esportes e o uso em abuso da Internet parecem influenciar na quantidade de horas dormidas. Por fim, as seguintes questões foram discutidas:

- Qual a conclusão da influência de cada variável estudada?

- Encontraram alguma coisa que tende a atrapalhar a quantidade de horas dormidas?

- Algum fator existente aumenta essas horas? 
Revista Ciências Exatas e Naturais, Vol.20 , nº.1, Jan/Jun, 2018

Os alunos observaram que o tempo gasto na internet, e a prática de esportes ou outras atividades físicas, podem influenciar no número de horas dormidas.

\subsection{Aplicação da Oficina 2}

Inicialmente o professor sugeriu as opções de temas citados acima e os alunos decidiram entre eles, que iriam trabalhar com os seguintes temas: Maioridade penal e Legalização do aborto, visto que consideraram os assuntos mais interessantes e discutidos na atualidade. Os alunos foram divididos em quatro grupos sendo um a favor e outro contra cada tema, citado anteriormente. Os grupos se reuniram para tratar como seria sua apresentação e quais meios de pesquisa seriam utilizados. Foi dado o prazo de duas semanas para que cada grupo elaborasse uma apresentação utilizando dados estatísticos para defender sua posição sobre legalização do aborto e maioridade penal.

O segundo momento da realização da oficina 2, ocorreu duas semanas depois de definidos os temas, e nesse momento cada grupo tinha um determinado tempo para expor sua apresentação em forma de seminário. Os dois primeiros grupos se posicionaram um a favor e o outro contra a legalização do aborto. O terceiro e o quarto grupos posicionaram-se um a favor e o outro contra a maioridade penal aos 16 anos. Para fundamentar seus argumentos os alunos se basearam em dados estatísticos adquiridas em pesquisas próprias e em fontes como internet, jornais e revistas. Na Figura 2 é possível ver alguns alunos em sua apresentação na atividade proposta na oficina 2.

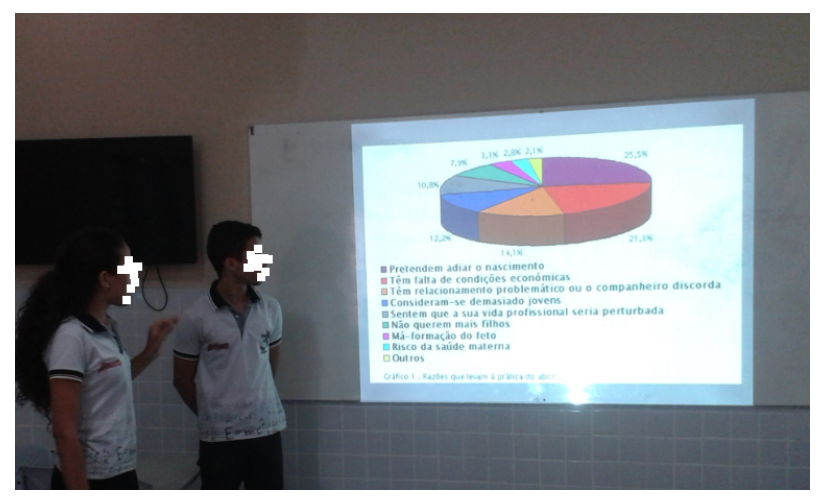

Figura 2. Alunos participando da Oficina 2

Os alunos participaram ativamente de todas as apresentações, tanto perguntando, quanto dando sua opinião sobre o tema. Ao final do trabalho, o professor ressaltou a importância do uso de dados estatísticos para embasar opiniões sobre determinados conteúdos e que a matemática está presente de forma fundamental em outras áreas do conhecimento.

\subsection{Aplicação da Oficina 3}

Inicialmente o professor dividiu os alunos em dois grupos: meninos e meninas. Cada aluno foi convidado a retirar sem a ajuda de uma fita métrica, uma medida de $50 \mathrm{~cm}$. Ficou decidido que os meninos retiravam de um rolo de fita azul e as meninas de um rolo de fita branca, e em seguida, escreviam seu nome no quadro branco e colavam a fita abaixo. Dando continuidade, o professor, juntamente com os educandos e o auxílio de uma fita 
métrica, anotou a medida real retirada por cada aluno separando os valores das meninas e dos meninos.

Depois desta etapa cada grupo calculou a média, a moda, a mediana, a amplitude, variância e o desvio padrão das medidas obtidas. Essas quantidades foram calculadas para cada grupo separadamente. Em seguida comparamos os valores, e foi possível verificar quem chegou mais próximo da medida desejada.

Nesta aula estavam presentes 15 alunos sendo 8 meninas e 7 meninos. Um fato bastante interessante e que contribuiu para uma melhor explicação dos conceitos das medidas que foram calculadas foi que uma das meninas retirou uma medida de 12 centímetros que é um valor muito distante de $50 \mathrm{~cm}$. As medidas para meninos e meninas podem ser vistas na Tabela 3.

Tabela 3. Medidas de posição e dispersão para os valores obtidas por meninos e meninas.

\begin{tabular}{c|cc}
\hline Medida & Feminino & Masculino \\
\hline Média & $45,25 \mathrm{~cm}$ & $59 \mathrm{~cm}$ \\
Mediana & $53 \mathrm{~cm}$ & $56 \mathrm{~cm}$ \\
Amplitude & $32 \mathrm{~cm}$ & $21 \mathrm{~cm}$ \\
Variância & $178 \mathrm{~cm}^{2}$ & $53,14 \mathrm{~cm}^{2}$ \\
Desvio padrão & $13,4 \mathrm{~cm}$ & $7,289 \mathrm{~cm}$ \\
\hline
\end{tabular}

Fonte:[8]

Para finalizar a aula, ainda foram abordados os conceitos e as diferenças existentes entre: média, moda, mediana, amplitude, variância e desvio padrão. Nesta parte o professor explicou por que apesar de o valor médio das medidas das meninas ter sido mais próximo do valor real do que o valor médio das medidas dos homens, o grupo dos homens teve medidas de dispersão menores. Isso se deu porque uma das meninas retirou uma medida muito distante de $50 \mathrm{~cm}$.

\subsection{Aplicação da Oficina 4}

Inicialmente o professor pediu que os educandos formassem duplas e entregou a cada dupla um dado. Neste caso, os dados eram supostamente honestos, visto que foram usados dados comuns e nenhuma alteração foi feita. Em seguida cada dupla lançou um dado seis vezes e, com base nos resultados deveriam decidir se o dado parecia ser honesto ou não. Depois, o professor construiu uma tabela no quadro onde anotou os resultados e as conclusões de cada dupla. Posteriormente, foi discutido em sala o conceito de inferência e constatou-se que seis lançamentos não é o suficiente para afirmar se um dado é honesto, pois o erro envolvido nesta estimação é muito grande.

Estendendo a discussão, o professor explicou que a inferência estatística possibilita estabelecer o tamanho da amostra que possa minimizar os possíveis erros envolvidos em uma pesquisa ou experimento, foram ainda tratados exemplos cotidianos de inferência como pesquisas de opinião pública. 
Revista Ciências Exatas e Naturais, Vol.20, nº.1, Jan/Jun, 2018

\subsection{Aplicação da Oficina 5}

Inicialmente o professor explicou como se daria a oficina, conforme foi descrita anteriormente.Os alunos formaram duplas e cada dupla jogou dez partidas do jogo mini trilha. A Figura 3 mostra imagens dos alunos jogando mini trilha em duplas.

Depois, calculou-se a frequência relativa das ocorrências das faces vencedoras (para cada dupla). Dando continuidade o professor pediu aos alunos um palpite sobre qual seria a probabilidade de vitória de cada face num próximo jogo. As duplas responderam de acordo com o resultado das dez partidas que haviam realizado, por exemplo se em uma dupla cara venceu 3 partidas e coroa 7 , então a dupla respondeu que a probabilidade de cara vencer era de 0,3 e a de coroa vencer era de 0,7. Após todas as duplas responderem o professor calculou no quadro a probabilidade (teórica) de uma partida terminar em cara ou em coroa.

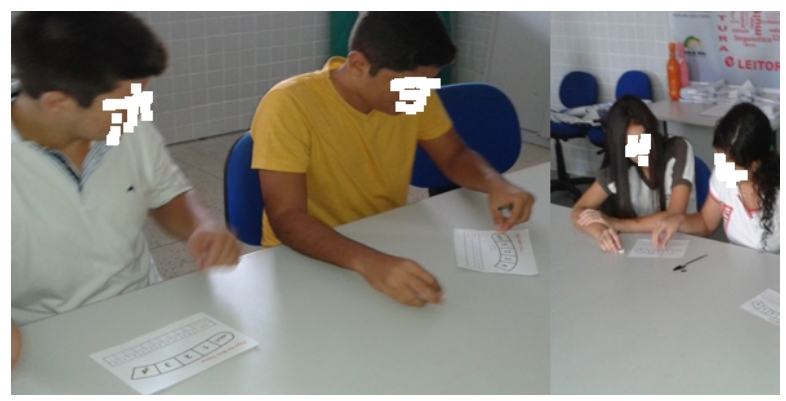

Figura 3. Alunos participando da Oficina 5

Na sequência, os resultados reais eram comparados com os dos alunos. O professor calculou a média aritmética das "probabilidades" estimadas de todas as duplas e encontrou a probabilidade de cara vencer igual a 0,33 e 0,77 para coroa e cara, respectivamente, que são valores bem próximos da probabilidade calculada na descrição da oficina.

Por fim, o professor discutiu com os estudantes sobre a honestidade das moedas que foram lançadas e observou que quanto maior for o número de lançamentos de uma moeda honesta maior será a proximidade da probabilidade clássica da vitória de cara ou coroa.

\subsection{Considerações Gerais}

Conforme foi dito, o trabalho foi realizado em uma turma de terceiro ano do ensino médio de escola pública. Inicialmente os alunos demonstraram pouco interesse em participar do projeto, visto que, já estavam no quarto bimestre e já haviam prestado ENEM (Exame Nacional do Ensino Médio). Mas, após ser apresentada a metodologia que seria utilizada, os mesmos ficaram curiosos e mais motivados a participar das atividades.

No decorrer da aplicação das oficinas foi possível perceber o entusiasmo dos alunos ao perceberem que poderiam aprender matemática de uma forma mais dinâmica e consequentemente, mais atrativa. Com as oficinas, conceitos estatísticos e probabilísticos, tais como, espaço amostral, população e amostra, medidas resumo, entre outros ficaram mais claros e perceptíveis. Um fator bastante interessante foi observar que os alunos que têm um baixo rendimento em matemática ficaram mais interessados, buscaram tirar dúvidas, questionaram e participaram efetivamente da aula, muitas vezes até mais do que os educandos que se destacam na disciplina. 
Dessa forma, as oficinas se tornaram uma ferramenta poderosa para melhorar o processo de ensino e aprendizagem de matemática, visto que, através desse tipo de atividade. Ficou claro que é possível enriquecer o conhecimento dos educandos mostrando a aplicação cotidiana da matemática e deixando de lado essa ideia carregada pelos alunos, desde o ensino fundamental, que esta disciplina é extremamente difícil de se aprender.

Enfim, após a realização das cinco oficinas, foi possível perceber que os alunos eram capazes de ler, interpretar e até mesmo construir gráficos e tabelas, como também calcular média, moda, mediana, amplitude, variância, desvio padrão entre outros, não apenas utilizando fórmulas prontas e de forma mecânica, mas sabendo realmente o conceito e o significado do que se estava calculando.

Ao final das oficinas, o professor se reuniu com os alunos e pediu que cada um desse seu ponto de vista sobre a metodologia utilizada. Todos os alunos elogiaram a metodologia utilizada e relataram que tiveram mais facilidade de aprender através das oficinas, visto que eles já tinham assistido aulas de estatística e probabilidade no decorrer do ano letivo. Entre os pontos citados pelos alunos, destacam-se:

- o fato das oficinas tornarem as aulas mais dinâmicas estimulou a busca pelo conhecimento, facilitando assim a aprendizagem através de aulas mais produtivas;

- a interação entre aluno e professor foi estimulada através do trabalho em grupo;

- o método muda o velho padrão, trazendo o conteúdo de forma lúdica e fazendo com que os alunos se envolvam mais;

- as atividades estimulam os alunos a opinarem e participarem diretamente da aula;

- nesse tipo de atividade, a Matemática é aplicada a outras áreas do conhecimento, e assim ajuda a desfazer o mito (por parte dos alunos) de que matemática não tem espaço no cotidiano das pessoas.

Além disso, os alunos sugeriram que este tipo de abordagem fosse usada por professores de outras áreas. Enfim, de acordo com os relatos dos alunos, pode-se constatar que as oficinas foram proveitosas e que as mesmas podem influenciar de forma significativa e concreta no processo de aprendizagem.

\section{Conclusão}

A proposta desse trabalho fez com que alunos do terceiro ano de uma escola pública tivessem a oportunidade de trabalhar a matemática sobre uma nova perspectiva, observando sua aplicabilidade social e ao mesmo tempo aprendendo de forma dinâmica e interativa. Sendo assim, o que se esperava era que os alunos fossem mais participativos e, consequentemente, aprimorassem seus conhecimentos em probabilidade e estatística, bem como compreendessem melhor as informações baseadas em dados estatísticos que eles acompanham pelos meios de comunicação.

$\mathrm{Na}$ opinião de muitos alunos, a matemática é uma disciplina considerada difícil e chata. Isso provavelmente acontece porque o conteúdo geralmente é ministrado de forma mecânica e sem o uso de atividades extra que possam fazer a ponte entre a teoria e a prática. Durante a aplicação das oficinas foi possível perceber envolvimento e participação por parte de todos os presentes. Além disso, os educandos a todo momento deixavam claro que estavam compreendendo melhor o conteúdo e que outros professores deveriam repetir a metodologia. 
Revista Ciências Exatas e Naturais, Vol.20 , nº.1, Jan/Jun, 2018

Antes de trabalhar as oficinas em sala de aula os alunos viram o conteúdo através de aulas expositivas que foram ministradas pela professora titular da turma. Em seguida, foram realizadas cinco oficinas, conforme descrito anteriormente. A primeira delas foi Horas dormidas. Nesta oficina os alunos tiveram a oportunidade de trabalhar com conceitos e construções de tabelas e gráficos utilizando o computador em alguns momentos e puderam também aprender na prática o que seria uma variável. Na segunda oficina, Argumentar com números, os educandos aprenderam a reforçar opiniões através de dados estatísticos, como por exemplo, se baseando em pesquisas. Na terceira Quem tem a melhor noção de medida, foi possível, através de uma aula dinâmica e interativa, fixar melhor os conceitos de medidas de tendência central e de dispersão. A Quarta oficina Seu dado é honesto?, fez com que os alunos compreendessem melhor os conceitos de amostra e inferência. A quinta e última oficina aplicada, Jogo da mini trilha, trabalhou de forma lúdica conceitos como: probabilidade, espaço amostral e inferência.

Todas as oficinas foram de suma importância, pois surtiram efeitos positivos na aprendizagem dos educandos. Vale ressaltar que as oficinas apresentadas neste trabalho são apenas algumas sugestões, pois existem várias outras atividades propostas que podem ser encontradas tanto no Ativestat (https://www.ime.usp.br/ativestat), que serviu de base aqui, como também no site do IBGE (http://eventos.ibge.gov.br/escolas-online) e, da Associação Brasileira de Estatística (http://www.redeabe.org.br/site/page_ manager/pages/view/canto-daeducacao).

Podemos concluir que a realização das oficinas atingiu o objetivo proposto, pois ao que tudo indica, os alunos se sentiram mais motivados e envolvidos. Obviamente, do ponto de vista do professor, é muito gratificante ver os alunos animados para aprender o conteúdo, inclusive aqueles que não têm muita afinidade com a disciplina. Para melhorar ainda mais o trabalho temos como proposta futura uma ampliação, onde poderíamos aumentar tanto o número de oficinas, quanto o número de turmas participantes, bem como trabalhar em conjunto com professores de outras áreas do conhecimento.

\section{Referências}

[1] ARAÚJO, S. P. A Estatística no Cotidiano Escolar: uma Experiência com Alunos do $3^{\circ}$ Ano do Ensino Médio. Dissertação (PROFMAT) - Universidade Estadual da Paraíba, 2015.

[2] BRASIL. Lei de Diretrizes e Bases da Educação Nacional. Brasília: MEC, 1996.

[3] BRASIL. Parâmetros Curriculares Nacionais: terceiro e quarto ciclos do Ensino Fundamental - Matemática. Brasília: MEC, 1998.

[4] DANTE, L. R. Matemática: Contexto e Aplicações. 2a. ed. [S.l.]: Editora Ática, 2013.

[5] GONÇALVES, P.A. Desenvolvimento de um Novo Objeto de Aprendizagem para o Ensino de Probabilidade no Ensino Médio. Dissertação (PROFMAT) — Universidade Estadual da Paraíba, 2014.

[6] IEZZI, G. et al. Matemática: Ciência e Aplicações. 6a. ed. [S.l.]: Atual Editora, 2010.

[7] LIMA, E. L. Matemática do Ensino Médio. 6a. ed. [S.l.]: SBM, 2006. 
[8] PEREIRA, Mailson M. Oficinas de Probabilidade e Estatística: Uma proposta de intervenção no ensino e aprendizagem de Matemática. Dissertação (PROFMAT) Universidade Estadual da Paraíba, 2017.

[9] VIEIRA, S. Elementos de Estatística. 6a. ed. [S.l.]: Editora Saraiva, 2010.

[10] VIRGILlitO, S. B. Estatística Aplicada. [S.l.]: Editora Alfa-omega, 2004. 